\title{
The Impact of Coronavirus (COVID-19) on E-commerce and Customer Spending Pattern in South Korea - e-Market Trends, Forecasts and Statistics
}

\author{
Kim Tae-Hwan \\ Department of Global Business Administration, AnYang University, South of Korea \\ Jeoung, So Yeon* \\ Department of Trade and Logistics, The Graduate School of Chung-Ang University of South Korea \\ E-mail: yooyoo2125@gmail.com
}

\begin{abstract}
Coronavirus (COVID-19) has caused a lot of disarray in all sectors across the world. Businesses have been significantly affected by the spread of the virus. Manufacturing, tours and travel, education, among other have been profoundly affected. A lot of strain has been exerted on most multinational operations. The pandemic has impacted retail trading. The need for e-trading and e-commerce has significantly increased because they promote distribution of products with minimal contact between the sellers and the buyers. This paper looks at how international trade has been impacted through addressing methods that have been employed to ensure that countries such as China and South Korea have managed to carry out their manufacturing processes and exportation. The paper explores the available literature regarding the purchasing behavior of prospective customers during the COVID-19 period. Data has been collected in different parts of the world to get facts about the impact of the pandemic. Market trends and future statistics forecasts have been provided. The research has also given possible recommendations that can be adopted by the World Health Organization and all the nations of the world to help in containing the COVID-19 and bring back sanity across the globe.
\end{abstract}

Keywords:COVID-19,E-commerce,Spending Pattern;South-Korea;e-MarketTrend

DOI: $10.7176 / \mathrm{JMCR} / 69-03$

Publication date:July $31^{\text {st }} 2020$

\section{Introduction}

The spread of coronavirus (COVID-19) continues to cause significant changes to businesses and the behavior of the consumers. The status of China which acts as the core of major supply chains has been greatly affected. A lot of strain has been put on multinational operations that carry out business both within the country and across the world. Among the sectors that have greatly hit include tourism industry and retail. According to Cheung (2020), this is because tourist industry acts as a major source of income for various markets. There was a great drop in the number of departures and arrivals of daily flights in the number of tourists between January 23 and February 13 from an average of 15,071 to a plenary 2,004. Most retailers have ended up closing their locations. Apple, for instance issued an announcement that it will not be able to meet the Q1 revenue guidance because of the disruptions that were taking place across the main supply chains in China. Businesses across the globe have shut down while others forced to scale down and cut their workflow. This dramatic pattern has negatively affected trade industry more so online markets where the certainty of delivery of goods is unpredicted. The pandemic has introduced the realization of the need for Electronic trading (E-trade) between countries as now more than ever there is a need for interconnection across the world. First, the fight for COVID-19 is global and every country has initiated measures within its boundaries to curb its spread of the virus and reduced the number of deaths.

\subsection{Justification}

The purpose of this research is to provide a clear and concise understanding of International trade, e-commerce and e-trade by giving specific information regarding customer behavior and spending pattern during COVID-19. The research addresses the various aspects of the trade and further expounds on the global impacts amid the COVID 19 pandemic. The deadly virus has greatly impacted trade and businesses globally and according to experts, it is going to take longer for normalcy to be regained and economies in different parts of the world, stabilized.

\section{Literature Review}

\subsection{The challenges of Traditional Retail and E-commerce face shifts}

With many cities being placed under lockdown, a number of brick-and-mortar retailers and restaurants found themselves dealing with the harsh realities after the local government implemented quarantine measures that restricted movements outdoors (Cheung, 2020). Major stores across the land such as Starbucks, Apple and Nike temporarily remained closed while the small and medium size retailers are facing the problem of reduced number 
of shoppers. Businesses across the globe have shut down while others forced to scale down and cut their workflow. This dramatic pattern has negatively affected the E-Commerce industry more so online markets where the certainty of delivery of goods is unpredicted. For instance, online markets rely on the trust of companies and organizations since customers from across the world spend money while entrusting the chosen companies to deliver quality services and goods. The shipping of products has been paralyzed as the majority of countries have banned travel including air and water. Therefore, shipments have been forced to take longer than before. The International Business Trading encompasses activities that facilitate the transfer of goods, services and resources across all borders. The spending habits of customers have therein been made to rely on a trustworthy payment method that is committed to market reliability (Mendoza, 2020).

Retail E-commerce sales in China 2019-2023 (in trillions and Percentage Change)

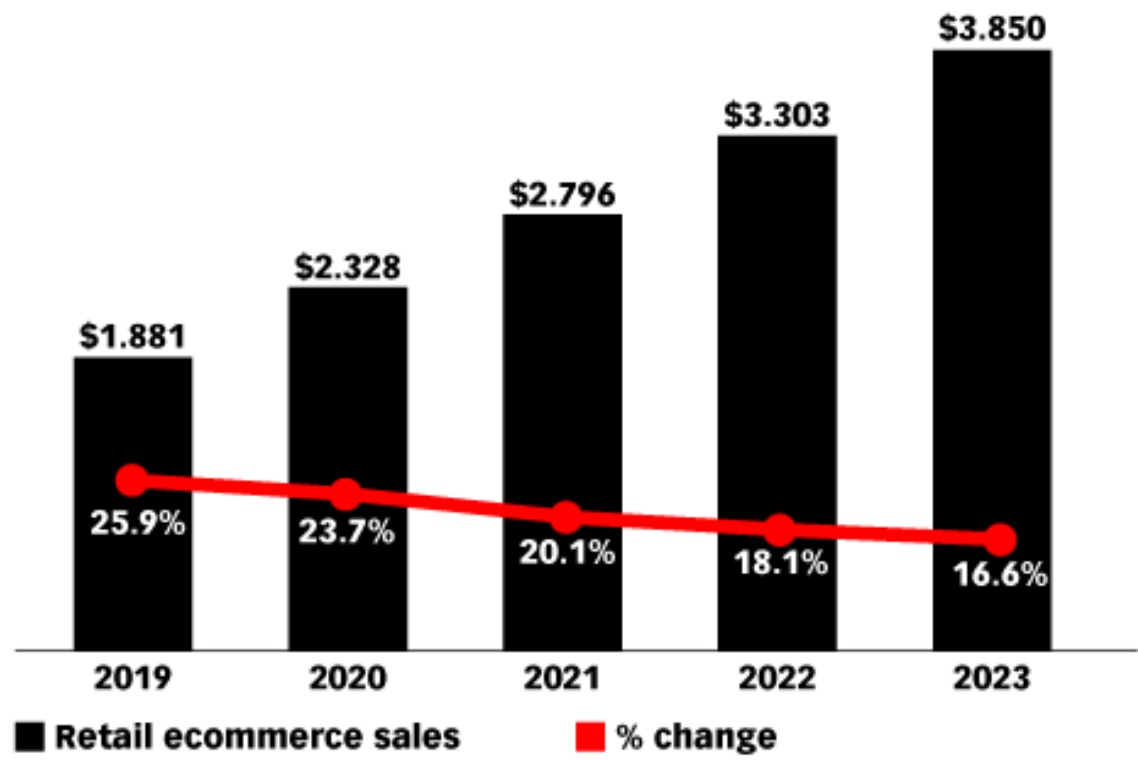

Figure 1.The graph includes products and services that are ordered through the use of internet through any device, irrespective of the means of payment or fulfillment.

\subsection{Increase in Time Spent Online}

COVID 19 resulted into the closure of places of entertainment such as movie theaters and theme sparks to minimize the chances of the spread of coronavirus. The circumstances greatly altered online behavior for China's consumers. The number of time spent on mobile internet has suddenly gone up from 6.1 hours in early January to 7.3 hours one month later when most of the people were placed in self-quarantine. And apart from the increase in mobile internet usage, there is a boost in traditional media too. Statistics indicate that television viewership went up after Lunar New Year, the time when there is always very low.

\subsection{Impact on Global Value Chains}

China has been crucial to the global economy in the last two decades. The rise of significance in the global economy is not just related to the associated status as a manufacturer and exporter of consumer goods but the country has become one of the main supplier of intermediate inputs for other manufacturing companies in other countries abroad. To date, $20 \%$ (up from $4 \%$ in 2002) of global trade in manufacturing intermediate comes from China. The figure below indicates the integration of China in the global value, in different sectors. The measurements are carried out by GLI. It is clear that Chinese manufacturing is vital in throughout the global value chains. Those that are related to precision instruments, communication equipment and machinery are highly essential. From the figure below, it can be said that any significant disruption of China's normal supply in this sector causes a substantial negative effect on producers in other parts of the world. Companies around the world are fearful that measures that were put in place to contain COVID 19 could definitely cause a shortage in supply of essential parts from Chinese republic and could therefore affect outputs across other parts of the world.

\subsection{E-Trade Items}


The COVID-19 pandemic has hugely affected E-Trade and e-trade items. For instance, stock markets have gone down and reduced drastically in different parts of the globe. The pandemic has delayed and stopped the flow of business in every way with various stock trading companies closing down. Generally, the eruption of the virus has brought about the unprecedented disruption of the global economy and world trade since the consumption of these items have scaled-down. E-trade items and services offered include common stocks, exchange-traded funds, fixed incomes, student loans, margin lending, online banking and cash management services. These items have been impacted differently amid the COVID-19 pandemic. For instance, as much as some have reaped big, others have been forced to crash and scale down (Baldwin et al, 2020).

The stock market exchange has been negatively impacted due to the COVID-19 pandemic. Sales have declined as well as the number of exchange rates. This is due to the impact on the economy that has slowed business. The dollar exchange rate for instance ranges differently in various countries. This trend cuts across all the dynamics in relation to trade. This is explained such that the COVID-19 pandemic has led to increased foreign trade among different nations to acquire PPEs, medicines and other essentials. Therefore, the increased foreign trade has necessitated the stability in the dollar due to its scarcity. The more increased the foreign trades the higher the dollar exchange rates. However, this does not apply to all e-trade items. In the case of online banking and cash service management, the activities have been on the rise. World Health Organization (WHO) advised the use of credit cards and online money services to avoid cash transfers that increase the spread of the virus. Therefore, the majority of items being bought have adapted the paperless transaction and in turn boosting online trade such as banking and online service management.

\subsection{What the stock Market talks about regarding Post-COVID 19 world}

In a stock market, a view of what the investors expect for the future is provided. It is during situations such as the outbreak of COVID 19 that the valuability of a market is determined. Most individuals do not sympathize with stock market but mostly associate it with speculations, scandals and greed. What they do not know is that the stock market can be a formidable tool within a society because it gives a unique view of the expected future of both a company and the general economy (Wagner, 2020). This is so because the value of a firm derives from all future expected cash flows that were discounted to the present to be able to adjust for both time and uncertainty. In the financial market, the possibility of all kinds of individuals to meet are quite high; the sophisticated and naive, opinionated and those without convictions to play a game with high stake like a pricing game. With a mix of fundamental value-drivers as well as demand and supply dynamics, there is the emergence of asset prices. To be precise, the stock market entails an incentivized survey of the possible outcome of the future. The situation is both complex and fast-involving situation, a situation that provides given useful information.

Travel industry almost came to a halt overnight when the government of China placed most cities across the country under lockdown and airlines cancelled their flights both within and outside the country. The ripple effects were evident across the world because the Chinese travelers make up to $10 \%$ of the international tourists. The tourists are a huge source of income for the tourism and retail industry. Between January 20th February 23rd, airline bookings reduced by almost half. The usual travels that are associated with Lunar New Year went drastically down by $50 \%$ and this marked its lowest point in a period of 20 years. It is projected that the airline industry is set to lose about $\$ 27.8$ billion in revenues from the coronavirus pandemic.

COVID 19 outbreak has brought about an epochal difference in the lives of many people. Initially, most managers, politicians and economists mainly concentrated on traditional business risks such as climatic changes. Within a short period of time, the attention has drastically changed and most governments across the world are trying the best they can to stem the tide with stringent measures. There exists a lot of uncertainty in that people do not know how deadly the disease is. We do not know whether there will be a vaccine and incase of its availability, the possible effects of the enacted policies and the manner in which people are likely to respond towards the situation (Wagner, 2020).

The prevailing event is a perfect opportunity to learn something regarding inventor psychology and the human behavior. At particular time, investors had started to speculate the direction the market was likely to take and trying to find out what other investors were speculating and how it would eventually turn out. Through digging deeper, additional and more essential patterns are discovered. And even as the aggregate market experiences feverish fluctuations and falls, relative stock price moves of different stocks is able to determine the kind of sectors and companies will be doing better in future compared to the others. The three phases of the investor behavior will be manifested and they include:

The first phase, also known as the incubation Phase started in early January after the detection of pneumonia was detected in the city of Wuhan, China. The most intelligent investors started speculating the most likely outcome. The investment behavior, for instance, resulted in a drop in the transport industry during the early phase. The second phase started after January 20 when the World Health Organization issued its first situation. Investors started being keen on the proceedings. Analysts on their part started talking about the coronavirus on conference calls and the search for 'coronavirus' in Google surged. There were some form of distress in the international 
oriented stocks, and there were clear signs that the global market was bound to be hampered for sometime in case the outbreak of the virus was nor contained within the shortest time possible. The performance of the telecom industry, it was clear that the investors expected demand for the services to go up, a clear indication that the mode of work would be highly relevant in the later days. February 24 marked the third phase. During this period, Italy implemented a strict lockdown within its areas that were most productive, for instance, Lombardy. There was a wild oscillation of markets. Most people suddenly came to the realization that the virus was likely to affect them directly. There was panic selling in the stock market which went hand-in-hand with panic buying in supermarkets. During this phase, there was the expected medium and long term from the relative stock price moves. Critically important, however, is that companies that had a lot of debts and experienced a shortage of cash started to undergo suffering disproportionally. This was a clear indication that the health crisis had already morphed into potential financial crisis.

Coronavirus pandemic represents a fearsome and a highly novel risk. Consequently, it stirred feverish behavior by the investors. Nevertheless, despite the panic, there were some reasonable economic expectations that supported the movements in the stock prices of specific individual companies. As a society, therefore, we are able to learn from the nature of the challenge that is being faced worldwide in these trying time. The reaction of the stock price is an indication of varied actions which entail fiscal policy interventions that should be put in place to alleviate further possible negative outcomes and measures that should be put in place to control COVID 19 shock. The prediction of the market situation foretells a different economic landscape compared to the one we are used to. These kinds of changes bring about possible social and political disorder. Hopefully, the inherent threats can be avoided and instead, benefit from the possible opportunities.

\subsection{Panic Buying}

When countries confirmed their first COVID-19 cases, there was a global market shift. For instance, the World Health Organization (WHO) created awareness to the public by stating and highlighting precautionary measures to prevent an individual from contracting the virus. The majority of people did not take this seriously until deaths were reported in large numbers. Some of the precautionary measures include wearing a mask, washing hands thoroughly with soap and running water and using sanitizers that contain above $70 \%$ alcohol content. This amounted to panic buying as supermarkets and shopping outlets were flooded with people who made their purchases. This thus led to shortages of some of these items on the shelves. Businesses took the advantage and flooded the e-commerce with different items and equipment where people would just shop online and the items are delivered at their doorsteps. For example, different kinds of sanitizers were sold on Jumia, Alibaba, Amazon and many others. This indicates the shift in market paradigms during this COVID-19 pandemic.

\subsection{Personal Protective Equipment}

The largest increase in e-commerce shopping was reported in Vietnam where $57 \%$ of the consumers do online shopping. This was followed by India at 55\% then China at 50\%. The virus is reported to have originated from Wuhan, China where 84, 311 people had contracted it with 4,642 deaths reported. The country initiated a total lockdown where there was no movement in and out of the country. Flights were banned and the focus was based on curbing a further spread. China is a superpower and contributes to a good percentage of international trade. The ban thus affected businesses hugely, with some almost collapsing. Nonetheless, the e-commerce managed to thrive through importation and exportation of PPEs that are largely needed globally. At some point, the United States, India and the majority of African countries depended on China for the importation of equipment in the fight against COVID-19. These included, masks, body bags, testing kits among others. In an online report, there existed a shortage of PPEs globally. (Park et al, 2020). This was due to the disruption of supply chains. With flights canceled and border ban restrictions, the shipment and transportation of these pieces of equipment have been slower than usual. For example, in March, India sought to acquire its masks and other protective gear from China through ecommerce. The supply of ventilators was also necessitated by the same. Through this, China's e-commerce grew by a huge margin thus boosting the economy as well as impacting lives.

\subsection{Customer Behaviors and Spending Patterns}

There has been a complete change in customer behaviors and spending patterns amid the COVID-19 pandemic. Generally, a comparison of spending habits before the pandemic and amid has shifted. Initially, people would lavishly spend their money on anything they like without caring with hopes of making more money. However, this has changed as people currently only spend money on essential things and tends to save more. According to an online statistic, 1 out of every 5 people can splash and spend money carelessly. This is because they invested and have savings that can last them a good while. The remaining are very cautious about what to buy and only buy food and other essentials. Also, lockdown, curfews, social distancing have shifted the behaviors of people and their spending habits. This is because they are confined in one place or region and cannot move around. Work, school and travel have also been suspended hence no need to purchase a new cloth, book an air ticket or reside in 
an expensive hotel (Rice et al, 2020). The majority of people dress up and look good to attend an event, travel or go to work. The current menace has however led to the closure of businesses including salons, boutiques among others. Therefore, people have resolved to stay at home, dressing casually and meeting their basic needs.

Peoples' lifestyles differ depending on their social class, wealth and type of jobs. In the wake of COVID-19, businesses have closed down and others scaled-down. Thousands have also been rendered jobless with no certain flow of money. This has in turn impacted customer behavior and uncertainty. More people have since resolved to save their finances due to the uncertainty of the pandemic as well as the life post Coronavirus. Further, customers are opting for businesses that offer goods and services at fair prices in comparison to the ones that are expensive and exaggerated. So many items are considered luxuries in certain households. With all the family members being home, the consumption level in the house is ideally increased. Therefore, food, water bills, electricity and other essentials are consumed twice than before or even more. Thus, customers have prioritized such against an expensive shoe or dress.

In an online publication on the daily COVID-19 insights, customer needs have been broken down and classified into three categories of the essentials, non-essentials and the new essentials. The essentials are the basic daily consumed items like food and beverages. The non-essentials are jewelry, expensive shoes and many more. The spending habits have thus been shifted and adapted into new essentials thus items that aid in the daily lives at this time of the pandemic. These are items like electronics such as computers for school, housewares including utensils among others. Thus, the deadly virus has created the prioritizing factors in customers' behaviors on spending.

The Current COVID-19 pandemic has impacted the purchasing behaviors of E-commerce community. Online shopping is one of the most frequented activities and during the COVID-19 era it has intensified in different parts of the world. The emergence of increased online markets has also impacted the customer purchasing behaviors in varied ways through beliefs, attitudes and intentions. There are certain people whose intentions, attitudes and beliefs fully support online e-commerce while others cannot dare to acquire any item or service online due to the same (Rasheed et al, 2020). This is because they might have had a bad experience shopping online where they ordered for something and the quality was compromised among other challenges. Ideally, in the case of people who fully trust e-commerce, it saves on time and has proven effective over the years as one does not have to spend time and money traveling to different regions in search of a particular product or item. Customer purchasing behaviors have also been necessitated by the online banking systems through the provision of electronic cards as exchange platforms for buying. Banks have provided credit cards, debit cards and visas that allow for global buying and selling without necessarily showing the faces or physical presence of the person. Therefore, a person can comfortably shop at the comfort of his/her home and make the payments via the electronic card, money is transferred from the customer to the client and the purchased items delivered. Therefore, different factors have influenced the purchasing behaviors of customers in the COVID-19 era. Among them is technology that is advanced and keeps improving to meet the customer and client needs.

\subsection{Implications of Korean Companies in e-trade of global companies}

E-trade has been widely adopted by Small-medium sized enterprises (SMEs) in Korea. This has been enhanced by useful new models that are widely competitive in the International trade markets. Korea is among the nations that have quickly grown and invented technological equipment that have speed up business and enable it to rank top on the international markets. According to Kim, e-commerce and e-trade impact international trade, directly and indirectly, depending on the labor markets (Kim et al, 2016). Consequently, e-trade thrives in the international market depending on the quality of goods and services offered as well as the type. Goods are categorized differently and some are fully essentials and on high demand in International trade. Korean markets have mastered this and have produced the goods and services that are highly demanded thus thriving in that sector. Korean companies have flooded the market and are very prompt in producing and releasing products. This has led to market saturation in that products are readily available lowering their prices and their demand. General statistics have proven that Korean products have flooded the International market thus increased competition.

First, Korean products are usually cheap in comparison to other countries in international trade. For example, Korean products such as mobile phones, computers and technological equipment are relatively cheaper as compared to those from the United States or Japan. This has led to increased international trade in Korea as people opt for cheap. However, some of their products are also not very genuine and have received complaints from different parts of the world. International trade thrives through competition and the quality of products and services offered. Therefore, with Korea providing items at cheaper prices, their products are opted for and in turn market prices are affected and drop. Thus, Korea markets have hugely impacted international trade and led to market saturation.

Secondly, ICT has been widely adopted by small businesses and has been categorized as growing areas. This is what has boosted the Korean markets to fall under the international trade markets. The Korean government has initiated ways to boost technology and SMEs to fall on the international map. It has instituted powerful to advance 
technologies and ensure it grows competitively with other market structures. For instance, due to the importance of innovations of ICT, businesses have developed products and services that boost the country thus enabling it to thrive in the international market. Some of the exports that have ranked Korea in the map of International trade ranks include Cars, vehicle parts, passenger and cargo ships, refined petroleum among others. These are products that are highly demanded and sell very well in the International markets (Choi et al, 2019).

\section{Research Questions}

The researcher used the following research questions to obtain the relevant information regarding the topic of study.

i. How has COVID-19 impacted business, trade, and e-commerce globally?

ii. How has e-trade changed in correspondence with technology and innovations over the years?

iii. What is the relationship between international trade and technological innovations?

iv. How has the Korean market impacted International trade?

v. How have customer purchasing behaviors changed over the years more so during the global COVID-19 pandemic?

\section{Methodology}

This section elaborates the techniques that the researchers used in the fact finding and analysis of the findings. This research used mixed methods of data collection; both qualitative and quantitative methods were employed. Primary data was obtained through observation of the daily trends while secondary Information was obtained from scholarly articles from experts, online sources, personal experiences depending on the surroundings and environment as well as presumptions and future predictions.

\subsection{Random Sampling}

This research detailed both qualitative and quantitative methods. First, quantitative research was used to address the statistical aspects. A random sampling method was carried in describing the impacts of COVID-19. For instance, an analysis of the statistical changes in international trade was compared before COVID-19, during COVID-19 and the predicted impacts post COVID-19. Online information on the same was also analyzed. For instance, online stock markets in different nations were randomly selected and their changes measured and monitored for a couple of days. Out of 10 randomly selected e-trade items a monitor was created to check the changes in market structure and demand. Consequently, customer behaviors were put on watch such that revenues for 10 major e-commerce companies were analyzed for a period of 10 days in comparison before and during COVID-19 (Etikana et al, 2016). This was possible through the use of graphs in that any slight changes were monitored and recorded to arrive at the final results.

\subsection{Ethnographic Research}

Sample information from different parts of the world was obtained. The distribution was done in order of the worst-hit to the least hit. Information regarding e-trade and e-commerce as well as the purchasing behaviors of the customers was taken. The decline and increase in various instances were recorded down and the conclusions arrived at. Ultimately, various revenues in e-trade were sampled and compared in ascending order. The ones with the lowest revenues generated from international trade during the COVID-19 era were recorded and analyzed to give the feedback needed in the research.

\subsection{Observations}

This was the most used research method in coming up with the required feedback in this research. This was done through reading through expert opinions, stock market predictions and changes as well as an observation of the global curve amid COVID-19. Numbers do not lie and thus proved effective in this method. Statistics of stock markets and international trade since January 2020 were analyzed and the various changes concluded as days progressed. Ideally, the COVID-19 pandemic hit the majority of European nations harder as compared to the African counterparts. Therefore, the two diversities were included in the research. There were analyses of online interviews with different heads on states, entrepreneurs and stock market gurus before the analysis was reached. For instance, world entrepreneurs including Jack Ma among others and their contributions to the economy during this time were analyzed (Choi et al). Further, business owners across the globe filled online questionnaires of the state of their businesses and the impacts that have been associated with COVID-19. These were fundamental in ranking and categorizing the SMEs in the international market. Studies dating back from 2010 were also synched in the research especially in Korean states to identify the gaps in the international trade as well as derive ways or solutions to address such gaps.

\subsection{Analysis}


This includes the measure of behaviors and categorizing the data to a meaningful element. For the qualitative data from the study, a six-phase textual thematic analysis was adopted to identify the categories of the themes (Braun \& Clarke, 2013). The statistical data were descriptively analyzed and summarized to explain the set of the emerging information. The methods used in this research are meant to identify the economic factors as well as countries that are more exposed to China's export disruption of the intermediate inputs. The analysis makes use of the United Nation's Statistics Division Trade Data (UNSDTD) that covers close to two hundred countries and thirteen sectors of manufacturing. Summarily, the integration of each country and industry with the Chinese economy is measured through the use of Grubel-Lloyd Index of the Intra-Industry trade.

Information obtained from the secondary data (The National Bureau of Statistics of China (NBSC) indicates a considerable decline in the output. China Manufacturing Purchasing Managers Index (PMI) which is one of the critical production indexes went down by close to 22 points in the month of February. There is a high correlation with exports and such a decline indicates a significant reduction in export by about $2 \%$ in annual basis. It can also be said that the drop that was seen in the month of February spread over the year is equal to - $2 \%$ of the supply of intermediate goods and services.

\section{Results}

\subsection{Gender Representation}

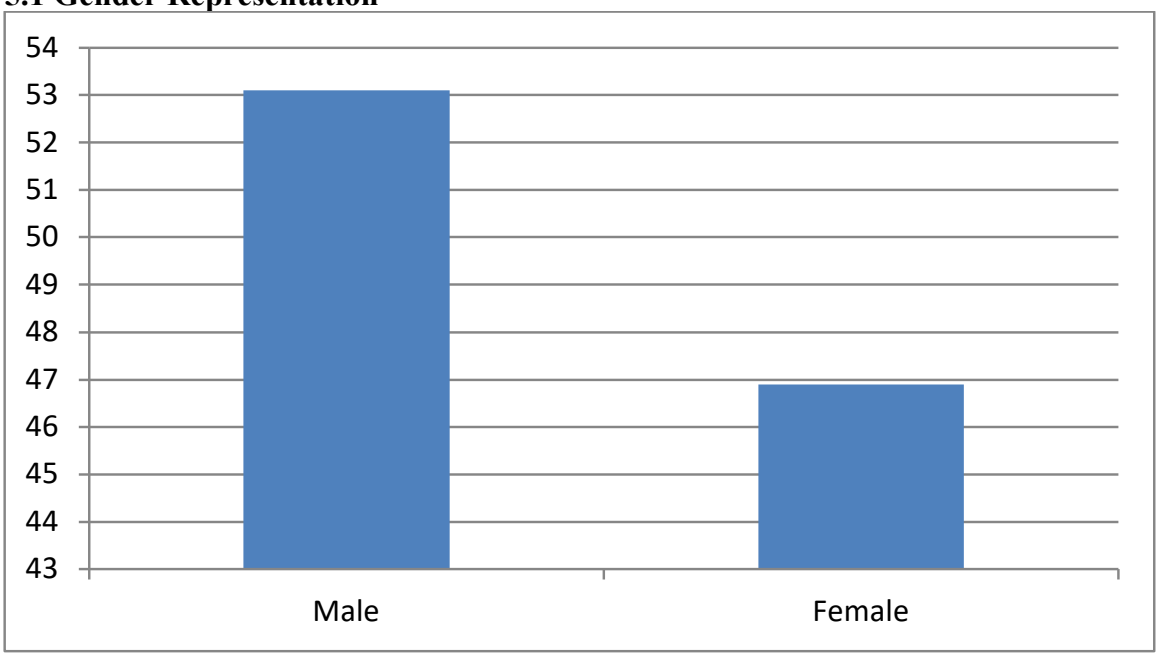

Figure 2. Gender Representation

There was an almost equal representation of both genders to ensure a balance opinion regarding the impact of COVID-19 on business, trade and e-commerce globally. The male gender was slightly higher at $53.1 \%$ compared to the female gender which was $46.9 \%$.

\subsection{The level of Qualification of the respondents}

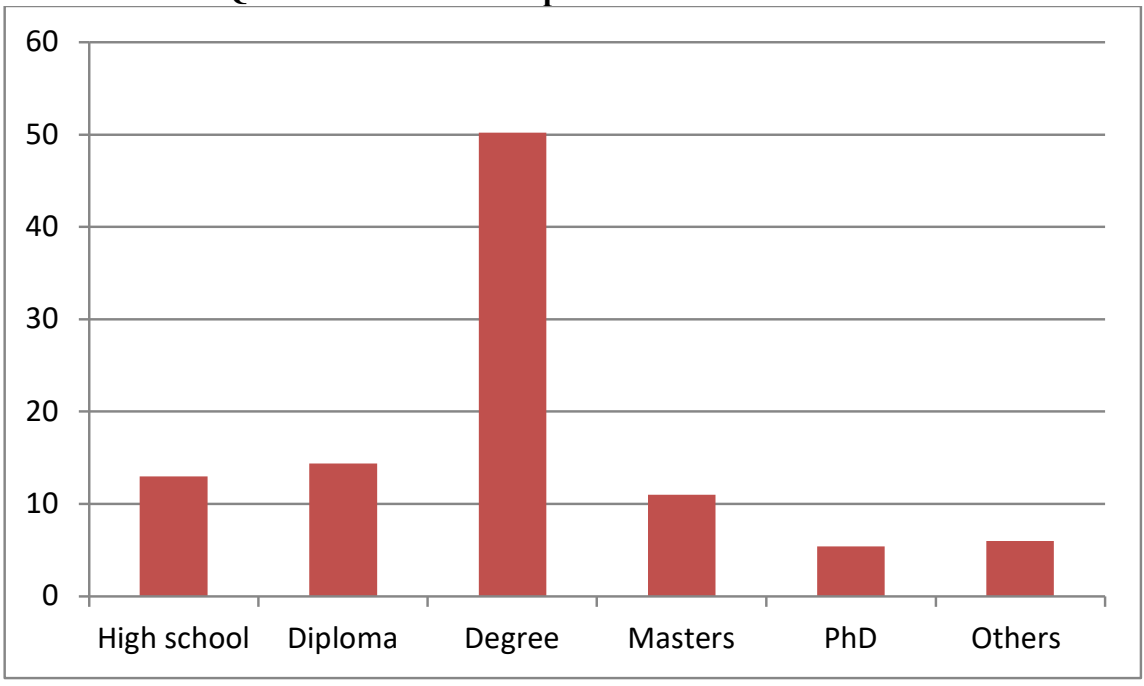


Figure 3. The level of Qualification of the respondents

The interviewer engaged learned people who are able to understand the impact of COVID 19 and how it has impacted the level of the economy. They were represented as follows; High school 13\%, diploma 14.4\%, Degree $50.2 \%$, Masters $11 \%$, Phd $5.4 \%$ while the rest were represented by $6 \%$. Those with the degree certificates were highly represented with a percentage of $50.2 \%$.

\subsection{How COVID 19 has impacted business, trade and e-commerce}

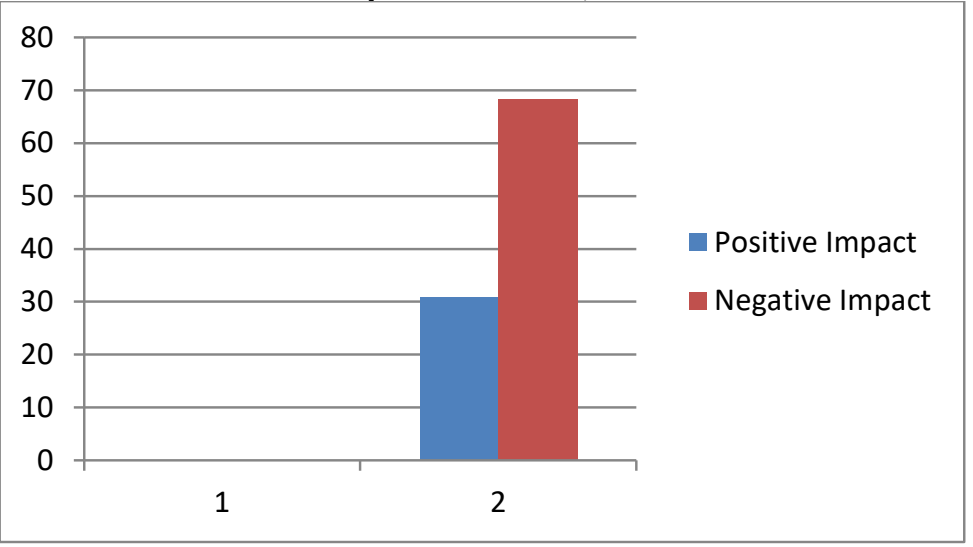

Figure 4. How COVID 19 has impacted business, trade and e-commerce

From the research information received, it was reported that the effects of COVID 19 were devastating. Most business schedules were cancelled in trying to contain the virus. The negative impact of COVID 19 was at $68.2 \%$ while $32.8 \%$ was positive. The latter represents the industries that came up due to the emergence of the virus and the equipment that were needed to contain it. Health equipments such as face masks, sanitizers, hand washes among others have been produced in large quantity. The importance of e-trade and e-commerce was also realized because it was the safest way to carry out the business since it entails minimal contacts and movement.

\subsection{Relationship between International Trade and Innovations}

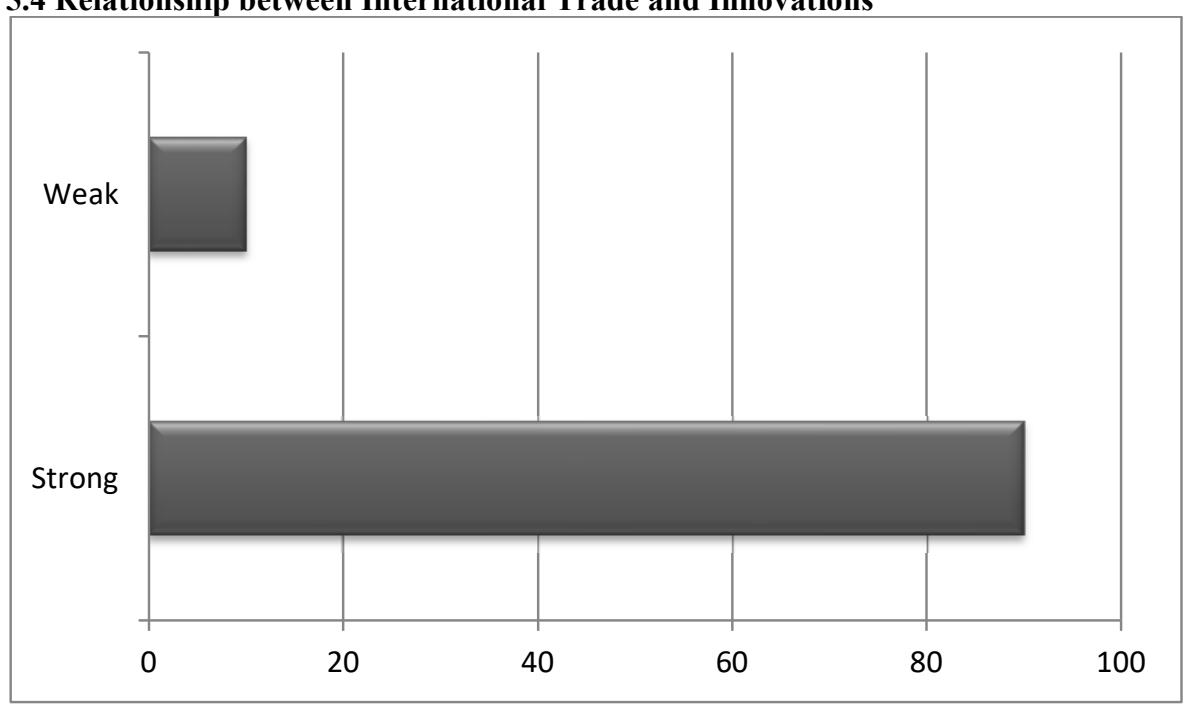

Figure 5. Relationship between International Trade and Innovations

According to the results received from the research, there is a strong relationship between international trade. International trade mainly depended on technological communication and transfer of finances through modern transfer methods. The trading partners across the globe have successfully managed to interact through video conferencing. Innovation and technology has played a great role in promoting e-commerce and e-trade. 


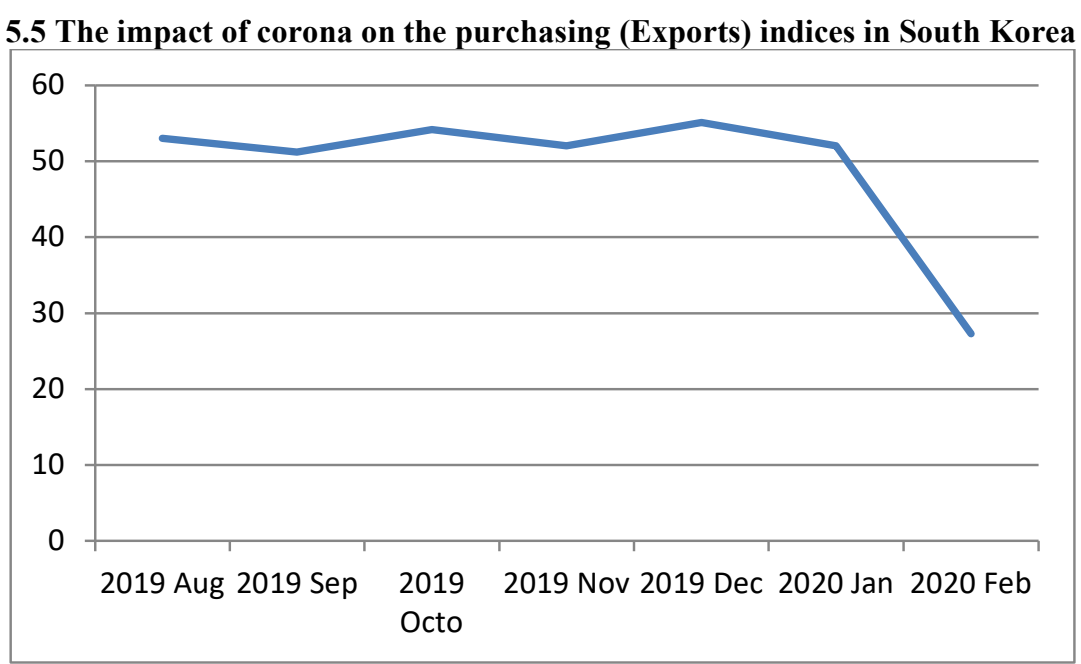

Figure 6. The impact of corona on the purchasing (Exports) indices in South Korea

Indicators on shipping also point out to a significant reduction in the level of South Korean exports for the month of February (From a high $55.1 \%$ to $27.3 \%$ ) as indicated in the graph above. According to the graph, container vessel departures from S. Korea were significantly lower during the month of February.

\subsection{Availability of Items due to Coronavirus}

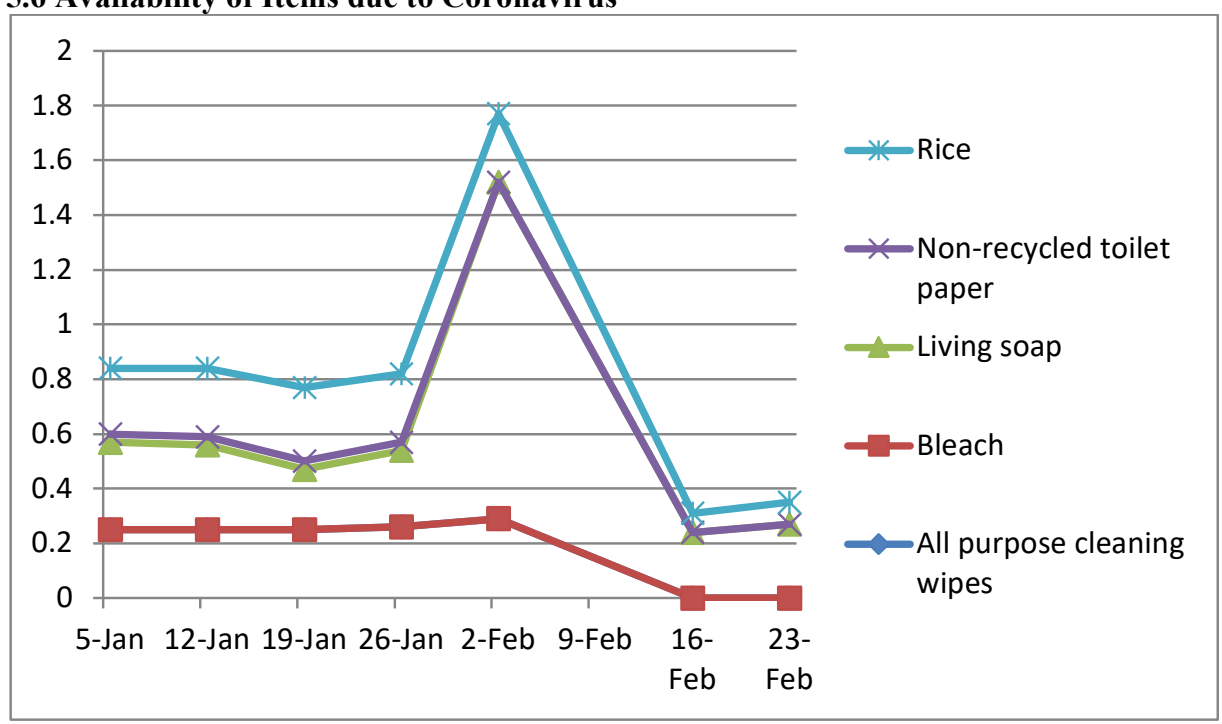

Figure 7. Availability of Items due to Coronavirus

South Korea has managed to keep a number of items in stock that have experienced high demand since the start of COVID 19. This was possible because of the strong logistical network of South Korea as well as the third part merchants. Categories such as cleaning wipes, rice and liquid soap experienced an increase in out of stock on e-commerce websites until February 9. Other increases were fairly negligible. E-commerce channel managed to recover to be able to manage the increased demand. Possibly this was possible due to the high reliance on third party merchants who sold the items through the online platforms.

\section{Discussions}

From the analysis, it is evident that COVID-19 is a global pandemic that has affected business, trade both locall and international differently. Some sectors of international trade have been impacted positively while others have been negatively impacted to the extent of the collapse. Businesses across the globe have shut down while others forced to scale down and cut their workflow. This dramatic pattern has negatively affected the E-Commerce and e-trade industry more so online markets where the certainty of delivery of goods is unpredicted. For instance, online markets rely on the trust of companies and organizations since customers from across the world spend money while entrusting the chosen companies to deliver quality services and goods. The shipping of products has 
been paralyzed as the majority of countries have banned travel including air and water. Therefore, shipments have been forced to take longer than before.

Though there is still uncertainty regarding the impact of COVID-19 on the productivity of China, the most recent statistics points to a significant downturn. The coming months are likely to give a clear picture of the full effects of coronavirus. Nevertheless, one of the questions that is of great importance is how the nature of disruption in the supply of Chinese intermediate inputs is likely to affect the rest of the world. Based on the above analysis, a number of factors are evident;

Even if COVID -19 is contained in China, the fact that the country supplies to other countries around the world means that any form of disruption that may be caused by restriction factors such as a lockdown will be greatly across other countries of the world. Countries within the European Union, America, and East Asia regional value chains will be greatly disrupted. The estimated global resultant effects can change based on the containment of the disease or changes in the source of supply of products.

It is also expected that the resultant spillover effects brought about by the disruption in Chinese supply is likely to be diverse in various economic sectors and will be dependent on the nature of geographic location of coronavirus outbreak and on the measures that have been put in place to contain its effects. For instance, automotive industry's intermediate exports may go down relatively more because the industry is geographically localized within the region where the outbreak of coronavirus took place.

According to online sources, the immigration policy imposed by United States President Donald Trump has also hugely impacted the exportation and importation of goods across the world. Multinational marketing has thus been necessitated through Cloud-Based International Platform Companies including Alibaba, AmazonWeb Services, Google, Oracle and many others. World e-commerce giants such as Jumia, Alibaba and Amazon have already experienced the impacts of COVID-19 due to the imbalance of meeting the customers' demands for essentials and other services (Mandel, 2017). Consequently, customer patterns and purchasing behaviors have been completely affected in some instances for the best while in others for the worst. The stock market however has thrived in different nations due to increased exchange rates and demand for stock exchange.

\section{Recommendations}

It is recommended that the world nations work together to enforce the World Health Organization measures that will ensure that the virus is successfully contained. Successfully control of the spread of the disease will enable us to go back to our normal duties. Measures such as social distancing, lockdowns of hot spot areas can help control the situation. Meanwhile, electronic trading and e-commerce can be embrace to ensure that people across the world are able to get the services and products they need.

The need for bridging the digital divide is deemed essential. This has to be done both within the country and across the boarders because of the importance of digital economy. The concept has played a significant role during this pandemic. There have been many traditional obstacles that have accentuated and continued to hamper the successful participation of e-trading and e-commerce activities. Producers, sellers, consumers in many developing countries have found it hard to cope up with the emerging trends of operations. There is need for efficient and affordable information and communication technology (ICT) services. Telecommunication, computer and emerging technologies must be emphasized by the various governments.

Governments and all private sectors need to adapt to new measures to positively respond and ensure that ecommerce helps in the alleviation of some of the challenges that faced during the fight against the deadly virus. Increase of network capacity, provision of expanded data services, lowering of costs, facilitation of digital payments as well as mobile money transfer are some of the measures that need to be embraced to help in combating the spread of the virus.

COVID -19 is a global pandemic and its impact on ecommerce can easily strengthen international cooperation. Consequently, this can help in the development of policies for online supplies and purchases. The virus has made it apparent that e-commerce can be an essential tool for consumers. E-commerce can easily support small businesses leading to a more competitive form of operation in various sectors.

The pandemic has to a great extend highlighted the significance of digital technologies in general. However, several vulnerabilities across the world have also been exposed. The experiences and lessons are vital to various discussions in World Trade Organization, including ecommerce, which is likely to benefit from a broader international cooperation to enhance cross boarder movement of goods and services, bridge digital divide and create a level playing grounds for micro, small, and medium sized enterprises.

\section{Conclusion}

International trade thrives perfectly well through technology and innovations. COVI-19 is a global pandemic that has created huge gaps in e-trading services which might take longer to recover and stabilize. As much as the exportation of PPE has increased, nationals globally are suffering due to its impacts that according to experts will take years to recover. The deadly virus has resulted in panic buying which has affected sectors of business. Ideally, 
learning, e-trade items and Korean SMEs will not remain the same. COVID-19 pandemic has created excessive turmoil across the world. The effect on supply and demand and the manner in which people work has been in the news globally and has been portrayed in the data provided above. The impact seems to be highly trivial relative to personal toll. Nonetheless, the task of ensuring that essential products such as food, medicine are able to reach to people around the world is vital as it will keep the society to continue functioning normally as the health experts work out on ways of containing the current pandemic. Therefore to add on appreciating the medical professionals, researchers as well as other for their exemplary efforts in treating the sick and working harder to try to find the cure, it is essential to appreciate people found in factories, distribution centers, delivery trucks, grocery points among others for helping in bringing items closer to people.

\section{References}

Alvarez, F. J. S. M. (2008). Trade marketing. Diversidades de objetos, unidades de objetivos, 147.

Baldwin, R., \&Tomiura, E. (2020). Thinking ahead about the trade impact of COVID-19. Economics in the Time of COVID-19, 59.

Braun, V., \& Clarke, V. (2013). Successful Qualitative Research: A Practical Guide for Beginners. London: SAGE.

Cheung, M. (2020). Coronavirus's Impact on the Consumers and Businesses in China. Retrieved May 3, 2020 from <https://www.emarketer.com/content/coronavirus-china-us-covid-19- impact-retail-travel $>$

Choi, M. J., \& Kim, K. K. (2019). Import Demand in Developed Economies \& Korean Exports (in Korean). Economic Analysis (Quarterly), 25(1), 34-65.

Etikan, I., Alkassim, R., \&Abubakar, S. (2016). Comparision of snowball sampling and sequential sampling technique. Biometrics and Biostatistics International Journal, 3(1), 55.

Hall, R. E., Jones, C. I., \&Klenow, P. J. (2020). Trading off consumption and covid-19 deaths. Stanford University Working Paper.

Hasanat, M. W., Hoque, A. Shikha, F. A. Anwar, M., Hamid, A. B. Tat, H. H. (2020).The Impact of Coronavirus (Covid-19) on E-Business in Malaysia. Asian Journal of Multidisciplinary Studies Vol. 3, No. 1, (2020)

Kim, H. M., \& Lee, H. H. (2016). Asset specificity and capability of e-Trade performance: evidence from Korea. Journal of Korea Trade.

Leavy, P. (2017). Research Design: Quantitative, Qualitative, Mixed Methods, Arts-Based, and CommunityBased Participatory Research Approaches. Guilford Publications.

Mendoza, A. R. (2020). (DP 2020-05) Trade in the Time of Corona: Broken Chains and Mended Barriers. UPSE Discussion Papers. < https://www.econ.upd.edu.ph/dp/index.php/dp/article/view/1528/1011 >

Park, C. Y., Kim, K., \& Roth, S. (2020). Global Shortage of Personal Protective Equipment amid COVID-19: Supply Chains, Bottlenecks, and Policy Implications. Retrieved April 21, 2020 from $<$ https://www.adb.org/publications/shortage-ppe-covid-19-supply-chains-bottlenecks-policy>

Rasheed, M. A. A., \& Khan, M. A. I. (2020). Correlation Between E-Commerce Infographics and Customer Shopping Behaviour: Evidence From GCC. Studies in Indian Place Names, 40(38), 533-537.

Spulber, D. F. (2008). Innovation and international trade in technology. Journal of Economic Theory, 138(1), 120.

Wagner, F. A. (2020). What the stock market tells us about the post-COVID-19 world. Retrieved May 3, 2020 from < https://www.nature.com/articles/s41562-020-0869-y> 